\title{
LA CONSTITUCIÓN DEL USUFRUCTO UNILATERAL
}

\section{THE CONSTITUTION OF THE UNILATERAL USUFRUCT}

JULIÁN SIGUAS RIVAS

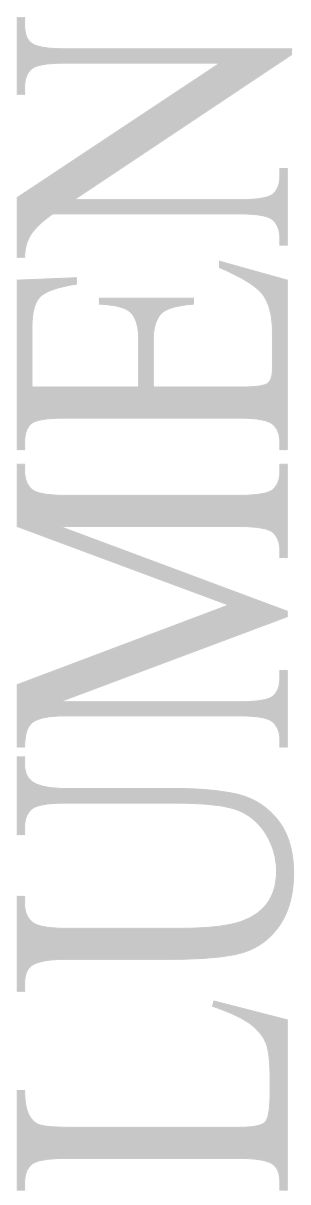




\title{
LA CONSTITUCIÓN DEL USUFRUCTO UNILATERAL
}

\author{
THE CONSTITUTION OF THE UNILATERAL USUFRUCT
}

Julián Siguas Rivas

\begin{abstract}
RESUMEN
El inciso 2 del artículo 1000 del Código Civil, establece como una modalidad en la constitución del Usufructo, el Ilamado Usufructo Unilateral; el mismo que es entendido como el constituido con la sola voluntad del propietario del bien a favor del usufructuario; declaración que está instrumentada en una Escritura Pública, su traslado es título suficiente para inscribir registralmente el mismo; ello por un desconocimiento de la institución y de sus elementos conceptuales; siendo la ratio del presente artículo establecer lo que debe entenderse por Constitución Unilateral de Usufructo.
\end{abstract}

\section{PALABRAS CLAVE}

Constitución del derecho de Usufructo. Usufructo Unilateral. Retención del Usufructo.

\begin{abstract}
Subsection 2 of Article 1000 of the Civil Code establishes as a modality in the constitution of the Usufruct, the socalled Unilateral Usufruct; the same that is understood as the one constituted with the sole will of the owner of the good in favor of the usufructuary; declaration that is instrumented in a Public Deed, its transfer is sufficient title to register it; this is due to a lack of knowledge of the institution and its conceptual elements; being the ratio of the present article to establish what must be understood by Unilateral Constitution of Usufruct.
\end{abstract}

\section{KEY WORDS}

Constitution of the right of Usufruct. Unilateral Usufruct. Retention of the Usufruct.

\section{INTRODUCCIÓN:}

Justifica las presentes líneas en que hace un tiempo, escuchando la exposición de un alumno sobre "Las modalidades de constitución del derecho real de usufructo"; éste al desarrollar la referida a la "Constitución del Usufructo Unilateral" contenido en el inciso 2 del artículo 1,000 del Código Civil, concluyó su alocución indicando que: Bastaba el Parte Notarial de la Escritura Pública en la cual con la sola comparecencia del propietario del bien inmueble y su declaración afectando en usufructo el mismo; y sin la intervención del usufructuario, expeditaba la inscripción en la partida registral del predio de dicho derecho.

Vencido el estupor e incredulidad ante lo referido, solicité al alumno sus fuentes y casuísticas por lo cual había entibado tal epitome.

El expositor avalaba su conclusión en las inscripciones registrales del que éste tenía conocimiento, así como de una simple interpretación literal del mencionado inciso que a la sazón parafraseó: "El usufructo se puede constituir por: (...) 2.- Contrato o acto jurídico unilateral"; y el acto jurídico unilateral era precisamente esa Escritura Pública en la cual unilateralmente el propietario de un inmueble declaraba su voluntad de constituir sobre el mismo el usufructo a favor del tercero.

Inquirido el auditorio sobre lo expuesto, éste en su mayoría resultó avalando lo sustentado, y en su minoría ante la seguridad de lo explicado y el cuestionamiento de lo mismo, no tomó postura esperando los contra argumentos - si los hubiere - para reafirmar o desasnar el criterio vertido. 
Partiendo de la experiencia que hay cosas más difíciles de explicar que de entender; y ante el reto de vencer un criterio enquistado mayoritariamente de comprender las cosas no por lo que son y causan, sino por las formas que se les dan, y que en derecho no es otra cosa que interpretar las instituciones jurídicas bajo el facilismo de la interpretación de lege lata de la normatividad avocada a ellas; solicité el tiempo mínimo necesario para elaborar la presentación argumental que defenestrara todo lo vertido en dicha clase.

\section{ARGUMENTOS LEGISLATIVOS EN PRO DE LO ASEVERADO:}

Observando un orden cronológico, nuestro Código Civil de 1852 no legisló de manera expresa al Usufructo Unilateral como una modalidad de su constitución. (1)

El Código Civil de 1936 tampoco tuvo articulado expreso sobre las formas de constituir el Derecho de Usufructo, aunque en su artículo 947 refería al usufructo convencional y al testamentario; además de diversos artículos que trataban diversos supuestos de usufructos legales, esto es constituidos por mandato legal; pero al igual que el código antecesor no legisló expresamente como una modalidad de su constitución el Ilamado Usufructo Unilateral.

Es el Código Civil actual, el que a guisa de cosa nueva, legisla sin antecedente expreso, el Ilamado Usufructo Unilateral.

Entonces un antecedente legislativo que cohonestara lo aseverado no existía.

\section{ARGUMENTOS EXEGÉTICOS DEL INCISO 2DO. DEL ARTÍCULO 1,000 DEL CÓDIGO CIVIL EN LA DOCTRINA NACIONAL:}

Al tratar de buscar argumentos exegéticos y doctrinales de pluma nacional al inciso 2 do. del artículo 1,000 del Código Civil, los resultados fueron:

1.- Doña Delia Revoredo de Debakey (2) en su Tomo $V$ de la Exposición de motivos y comentarios del Código Civil, al igual que don Max Arias-Schreiber Pezet (3) en su Exégesis del Código Civil de 1984; al desarrollar dicho artículo, sólo desarrollaban como tema principal la posibilidad de prescribir adquisitivamente el derecho de usufructo; mas nada del llamado usufructo unilateral.

2.- Don H. Gustavo Palacio Pimentel (4) no desarrollaba al Ilamado Usufructo Unilateral; mientras don Alberto Vásquez Ríos (5) asimiló al Usufructo Unilateral con el Usufructo Testamentario, ya que, según su explicación es el testamento el acto jurídico unilateral por excelencia.

Hasta aquí, los autores de mayor referencia en el medio, no aclaraban el tema que, si era posible que con la sola declaración del propietario contenida en una Escritura Pública se constituyera un Usufructo y expeditara la inscripción en la partida registral del inmueble materia del mismo; todo ello sin necesidad de la intervención del usufructuario; dejando constancia de lo dicho hasta aquí, que - discrepando con todo el respeto y consideración al maestro extinto Vásquez Ríos - no podía entenderse lo mismo el Usufructo Unilateral con el Usufructo Testamentario.

\section{DESBROZANDO LA INCÓGNITA:}

De los literatos contemporáneos uno de los más acuciosos es don Gunter Gonzales Barrón quien partiendo de la discrepancia total sobre la posibilidad que mediante una sola declaración de voluntad se genere derechos a favor de terceros, sin que estos intervengan aceptando dicho derecho; termina estableciendo los supuestos del llamado usufructo unilateral diciendo: 
"Ello ocurre en los casos en que el propietario decide enajenar la propiedad del bien, pero se reserva a sí mismo el usufructo. Este negocio llamado en doctrina de "Reserva de usufructo" constituye un acto unilateral del propietario a favor de sí mismo, quien simultáneamente celebra un negocio coaligado de enajenación. (...) Este acto de "reserva" que es relativamente frecuente cuando va acompañado de negocios gratuitos de enajenación." (6)

A cuyas ideas se adhieren lo aseverado por doña Moraima Ferradas Reyes (7) en su comentario realizado al artículo 1,000 del Código Civil, que aunque esta en forma demasiado lacónica deja entrever otra idea de lo que podría ser el Usufructo Unilateral, aseverando en cuanto a la creación del derecho real del mismo que:

"Un contrato puede crear un derecho de usufructo de dos maneras: ya sea por vía de la constitución directa o enajenación, caso en el cual el constituyente atribuye al adquirente el derecho de usufructo y conserva la propiedad; o por vía de la detracción o reserva, en cuyo caso el constituyente enajena la propiedad y se reserva el usufructo."

\section{PROPUESTA ADECUADA DEL CONCEPTO:}

De lo aseverado por Gunther Gonzales y Moraima Ferradas, podíamos desdeñar el criterio original de lo que creíamos hasta ahora el Usufructo Vitalicio legislado en el 2do. inciso del artículo 1000 del Código Civil; esto es:

"La Escritura Pública unilateral suscrita sólo por el propietario sin intervención del usufructuario en la cual se constituía y expeditaba inscripción el usufructo sobre el inmueble en cuestión."

Toda vez que ahora había nuevos elementos conceptuales, esto es:

La enajenación del Derecho de Propiedad,

La reserva del usufructo (detracción)

El negocio coaligado de enajenación

\section{PESQUISA LITERARIA:}

Se dice que la antigüedad es clase; y que mejor que mostrar ello, con lo aseverado por uno de nuestros eximios juristas, me refiero a Jorge Eugenio Castañeda, que en época bajo la vigencia del Código Civil de 1936 teorizaba sus figuras, entre ellas la del Usufructo diciendo:

"Puede el constituyente reservarse el usufructo de la cosa y transferir la propiedad de la misma a un tercero. Puede también conservar la nuda propiedad y otorgar el usufructo a un extraño; o no conservar nada y dar la nuda propiedad a uno y el usufructo a otro u otros. (...) Esta voluntad puede manifestarse por acto entre vivos o por testamento." (8)

El primer párrafo coincide con el concepto y la idea presentados por Gunther Barrón y Moraima Ferradas; y lo que es mejor aún al indicar que ello puede ser por acto "entre vivos" descarta el criterio que baste una sola declaración de voluntad para constituir el derecho; estando presente el llamado negocio coaligado de enajenación.

Fijémonos lo que nos enseña el clásico español don José Luis Lacruz Berdejo al decirnos en su obra sobre la constitución del usufructo por acto inter vivos, que: "Puede ser a título oneroso o gratuito. La constitución por contrato es menos frecuente y su forma más habitual es la transmisión de la nuda propiedad de una finca al adquirente, reteniendo el antiguo dueño pleno el usufructo vitalicio." (9) 
Lo que es seguido contemporáneamente por el español don M. Clemente Meoro quien a su decir el usufructo voluntario puede realizarse por vía de traslatio o enajenación, atribuyendo el constituyente el usufructo y conservando la nuda propiedad, o por vía deductio o retención, reservándose el constituyente el usufructo y transfiriendo la nuda propiedad. (10); y por su coterráneo Alejandro Díaz Moreno, quien apostilla lo dicho que en cuanto a la constitución del usufructo "cabe este por contrato (...) Inter vivos puede tener lugar por vía de enajenación o por vía de retención. En el primer supuesto el objeto del contrato lo constituye el mismo derecho de usufructo, operándose una traslación de la posesión y del goce en favor de quien ante no la tenía. En el segundo supuesto, el propietario enajena la nuda propiedad reservándose el usufructo, de manera que no hay desplazamiento en cuanto al goce." (11)

\section{CONCLUSIÓN:}

Es posible ya concluir que el supuesto teórico contenido en el inciso 2 del artículo 1000 de nuestro Código Civil referido a la posibilidad de constituir un Usufructo Unilateral, no tiene nada que ver con las declaraciones de voluntad (una sola), ni que esta única voluntad contenida en una Escritura Pública sea suficiente para inscribir la carga (usufructo) en la partida registral del predio sin que intervenga aceptando el usufructuario la misma; sino a lo que la doctrina llama:

La Reserva del Usufructo

Retracción del Usufructo

Usufructo Vía deductio

Usufructo vía Retención

Nomen iuris cuyos supuestos son el que: El propietario declare que retiene el usufructo del bien, transfiriendo el derecho de propiedad al adquiriente sin el mismo; y ello con el pleno acuerdo del adquiriente.

Ese es el supuesto del llamado por nuestro Código Civil en su inciso 2 del artículo 1000 Usufructo por Declaración Unilateral.

De la conclusión podemos establecer lo utilitario del concepto:

"La teoría sin la praxis o acorde a ella es estéril, relamida y hueca; pero la praxis sin la teoría es mucho peor ya que pretende ocultar su fealdad embozándose en interpretaciones de lege lata."

Digo esto porque, las mejores discusiones no se dan en el vacío, sino motivadas por un problema real.

Supongamos que unos padres, propietarios de un inmueble desean que su hijo menor de edad sea el nuevo propietario del mismo, pero que a su vez, estos puedan seguir usufructuando el bien hasta que fallezcan.

Tendrían dos opciones:

1) Otorgar la Escritura Pública de transferencia de dominio a título gratuito (donación pura o anticipo de herencia) y en una Cláusula Adicional constituir en representación del menor el usufructo vitalicio a su favor; en cuyo caso tendrían que obtener la Licencia para Gravar bienes de menores en vía judicial como cosa previa, porque sin ella no podrá darse por constituido ni mucho menos inscribirse el Usufructo; o 
2) Otorgar la Escritura Pública de Constitución de Usufructo Vitalicio a su favor; y en una Cláusula Adicional transferir a título gratuito (donación pura o anticipo de herencia) a favor de su hijo menor de edad el derecho de propiedad del bien.

Si la respuesta es lo segundo; habrá cumplido su finalidad el presente artículo.(12)

\section{REFERENCIAS:}

- $\quad$ Aunque si estableció el supuesto del mismo en el artículo 1099 inciso 4 al desarrollar como supuesto de la fianza el llamado usufructo unilateral.

- $\quad$ Arias-Schreiber Pezet, Max y Cárdenas Quiroz, Carlos. Exegesis del Código Civil de 1984 Tomo V Derechos Reales. Walter Gutiérrez C. Editor Lima 1993 págs. 156 y 157

- Castañeda, Jorge Eugenio Instituciones de Derecho Civil Los Derechos Reales Tomo II Ed. Derechos Reservados Lima 1958 pág. 108

- $\quad$ Ferradas Reyes, Moraima. En Código Civil Comentado por los 100 mejores especialistas. Tomo V Derechos Reales. Ed. Gaceta Jurídica S.A. 2003 Lima. Págs. 631 y 632

- Gonzales Barrón, Gunther. Derechos Reales Ed. Jurista Editores. Lima 2005 Pág. 1043• Palacio Pimentel, H. Manual de Derecho Civil Tomo I. Ed. Huallaga Lima. pág.439

- Lacruz Berdejo, José Luis y otros. Derechos Reales Volumen Segundo Derechos Reales Limitados Situaciones de Cotitularidad. Ed. JMB S.A. Barcelona 1991 pág. 20

- Obra Colectiva. Derecho Civil Derechos Reales y Derecho Inmobiliario Registral. Coordinador M. Clemente Meoro. Ed. Tirant To Blanch Valencia 2001 pág. 312

- Obra Colectiva. Lecciones de Derecho Civil Derechos Reales e Hipotecario. Ed. Tirant To Blanch Valencia 2014 pág. 191

- Revoredo de Debakey, Delia. Código Civil V Exposición de Motivos y Comentarios. Derechos Reservados. Lima. 1988 págs. 213 y 214

- Se recomienda revisar lo resuelto por el Tribunal Registral en sus resoluciones Nros. 441-2018-SUNARP-TR-T del 20 de Julio del 2018 y 032-2018-SUNARP-TR-A del 18 de Julio del 2018 en http://www.sunarp.gob.pe/tribunalregistral

- Vásquez Ríos, Alberto. Los Derechos Reales La Propiedad. Ed. San Marcos Lima 2003 Pág. 220 